\title{
Cervical cancer in women aged 25 years or younger: a retrospective study
}

This article was published in the following Dove Medical Press journal: Cancer Management and Research

\section{Yujia Kong \\ Liju Zong \\ Junjun Yang \\ Ming Wu \\ Yang Xiang}

Department of Obstetrics and Gynecology, Peking Union Medical College Hospital, Chinese Academy of Medical Sciences and Peking Union Medical College, Beijing, People's Republic of China
Correspondence: Yang Xiang Department of Obstetrics and Gynecology, Peking Union Medical College Hospital, Chinese Academy of Medical Sciences and Peking Union Medical College, No.I Shuaifuyuan, Dongcheng District, Beijing 100730, People's Republic of China

Tel +86 1065296068

Fax +861065296068

Email xiangy@pumch.cn
Purpose: The incidence of cervical cancer in young women is increasing. This study aimed to analyze the clinicopathological characteristics, treatment, and prognoses of women aged $\leq 25$ years with cervical cancer.

Patients and methods: Medical record data of 60 cervical cancer patients aged $\leq 25$ years treated at Peking Union Medical College Hospital between January 1986 and December 2017 were reviewed. The overall survival rate was estimated using the Kaplan-Meier method. Prognosis-related risk factors were analyzed using univariate and multivariate analyses.

Results: Among the 60 patients, 44 (73.3\%) were diagnosed with cervical carcinoma and 16 (26.7\%) with cervical sarcoma. In the cervical carcinoma group, the most common histology was squamous cell carcinoma $(n=22,50.0 \%)$ followed by adenocarcinoma $(n=18,40.9 \%)$. Notably, clear cell carcinoma dominated cervical adenocarcinomas at $61.1 \%(11 / 18)$. In the cervical sarcoma group, embryonal rhabdomyosarcoma comprised $50 \%$ of the cases $(8 / 16)$. A total of eleven patients with cervical carcinoma underwent fertility-sparing surgeries, and the live birth rate approached $66.7 \%$. The estimated 5 -year overall survival rate of the entire cohort was $79.8 \%$ with no statistically significant difference between the carcinoma and sarcoma groups (74.3\% vs 93.3\%, $P=0.14$ ). Stage (RR 6.71, 95\% CI 1.366-32.970, $P=0.019$ ) and lymph node metastasis (RR 9.09, 95\% CI 1.050-78.732, $P=0.045$ ) were independent risk factors for poor prognosis in those young patients with cervical carcinoma.

Conclusion: Adenocarcinoma and sarcoma of the cervix comprise the majority of cervical cancer in young women; their overall prognoses are not worse than older patients; the survival rates tend to vary widely according to histologic subtypes.

Keywords: cervical cancer, young women, histologic subtypes, fertility preservation, prognosis

\section{Introduction}

Cervical cancer is the fourth most common cancer and the fourth leading cause of cancer-related mortality in women worldwide. Approximately 570,000 new patients were estimated to be diagnosed in 2018, with 311,000 deaths projected. ${ }^{1}$ Over the last few decades, the incidence and mortality rates of cervical cancer have declined owing to population-based cervical cancer screening programs and anti-human papillomavirus (HPV) vaccines. ${ }^{2}$ However, according to epidemiological studies, the incidence of cervical cancer in young women is increasing. Patel et $\mathrm{al}^{3}$ reported that the incidence of cervical cancer in women aged 20-29 years increased annually by $10.3 \%$ between 2000 and 2009. The mean age at cervical cancer diagnosis was 5-10 years younger than that reported before 2000 in the People's Republic of China, and patients aged 35 years or younger accounted for $16 \% .{ }^{4}$ Another study also showed that the cervical cancer 
mortality rate increased from 0.1 to $0.2 / 100,000$ population in Japan. ${ }^{5}$ Some previous studies reported that young cervical cancer patients had worse prognoses and lower survival rates than older patients, ${ }^{6,7}$ while other investigations found that age was not associated with poor prognosis. ${ }^{8,9}$ Moreover, previous studies have shown that cervical adenocarcinoma appears to be increasing rapidly in young women. ${ }^{10,11}$ The reason why adenocarcinoma is more likely to be found in young women is that HPV types associated with adenocarcinoma are more prevalent in younger women, including HPV-18 and HPV-45. ${ }^{12}$ Several studies have demonstrated that adenocarcinoma has a worse prognosis than squamous cell carcinoma because it is more likely to progress rapidly and often escapes detection. ${ }^{6,13-18}$ Furthermore, most young patients with cervical cancer desire to preserve their fertility, which complicates treatment options. Consequently, it is critical to attain a better understanding of cervical cancer in women aged $\leq 25$ years. However, data in this age group are limited. Additionally, invasive cervical cancer develops over 5-10 years in $20 \%-30 \%$ of patients with cancer precursors. ${ }^{2}$ However, among cervical cancer patients $\leq 25$ years, the majority of them probably do not have a $>5-10$ years history of HPV infection or cancer precursors. Hence, we postulate that cervical cancer in young women aged $\leq 25$ years is likely to be more aggressive.

Therefore, we conducted this retrospective study to analyze the clinicopathological characteristics, treatments, and prognoses of young women with cervical cancer (defined as patients 25 years old or younger). To the best of our knowledge, this study comprised the largest sample size of cervical cancer patients aged $\leq 25$ years and reveals the prognoses of cervical cancer on this age group for the first time.

\section{Patients and Methods}

Between January 1986 and December 2017, we identified all cervical cancer patients aged $\leq 25$ years who were treated at Peking Union Medical College Hospital (PUMCH) - a class A tertiary comprehensive hospital in Beijing, People's Republic of China. Patients with cervical carcinoma or cervical sarcoma confirmed by pathological diagnosis were included. We reviewed the database and medical records to extract demographic and clinicopathologic data including age at diagnosis, age at first intercourse, number of sexual partners, marital status, symptoms (post-coital bleeding, abnormal vaginal bleeding, cervical polypoid mass, abnormal cervical cancer screening tests and others), stage, histologic subtype, differentiation, tumor size, surgical treatment, parametrial involvement, lymphovascular space involvement (LVSI), deep stromal invasion (DSI), lymph node (LN) metastasis, surgical margin status, and any radiotherapy and/or chemotherapy treatments. Surgical procedures included conization, radical trachelectomy, radical hysterectomy for cervical carcinoma, and polypoid mass resection for sarcoma. This study was approved by the Ethics Committee of PUMCH. Owing to the retrospective study design and analysis of clinical data, informed consent was formally waived by the Ethics Committee of PUMCH. All patient information is ensured to be confidential. All the procedures in this study are in accordance with the Helsinki Declaration.

All the patients were followed either through telephone interviews or at outpatient clinics until November 2018. The survival time was defined as the interval between the date of diagnosis and that of death or last follow-up. The overall survival rate was estimated using the Kaplan-Meier method, and rates were compared using the log-rank test with univariate analysis to identify prognostic risk factors related to survival. Factors found to be associated with survival on univariate analysis were subjected to a Cox proportional hazards model. $P$-values (two-tailed) of $<0.05$ were considered statistically significant. Statistical analyses were performed using the SPSS Version 25.0 statistical software (IBM Corporation, Armonk, NY, USA).

\section{Results}

Between January 1986 and December 2017, 5,833 patients with cervical cancer who were treated at PUMCH were identified. Sixty of these patients were 25 years or younger (1.0\% of the cervical cancer patient population). The patients' demographic and clinical characteristics are summarized in Table 1 . The median age at the diagnosis of cervical cancer was 23 years old. Among the 60 young patients, 44 (73.3\%) were diagnosed with cervical carcinoma and $16(26.7 \%)$ with sarcoma. In the cervical carcinoma group, the most common histology was squamous cell carcinoma (50.0\%) followed by adenocarcinoma (40.9\%). Notably, clear cell carcinoma of the cervix (CCCC) comprised 61.1\% (11/18) of adenocarcinomas; 8 (72.7\%) of which were pre-sexual debut. In the cervical sarcoma group, embryonal rhabdomyosarcoma (ERMS) comprised half this patient subpopulation $(8 / 16)$ while endometrial stromal sarcoma afflicted 25\%. Nearly $77 \%$ of cervical carcinoma patients had engaged in sexual activity before diagnosis; the median age at first intercourse was 19 years, and eleven patients had three or more sexual partners. In contrast, the majority of cervical sarcoma patients had never been sexually active. More than $80 \%$ of patients with cervical carcinoma presented with post-coital or abnor- 
Table I Demographic and clinical characteristics of cervical cancer patients aged $\leq 25$ years

\begin{tabular}{|c|c|c|c|c|c|c|}
\hline \multirow[t]{3}{*}{ Clinical characteristics } & \multicolumn{2}{|c|}{ Cervical carcinoma } & \multicolumn{2}{|c|}{ Cervical sarcoma } & \multicolumn{2}{|c|}{ Total cohort } \\
\hline & \multicolumn{2}{|c|}{$(N=44)$} & \multicolumn{2}{|c|}{$(N=16)$} & \multicolumn{2}{|c|}{$(\mathrm{N}=60)$} \\
\hline & $\mathbf{n}$ & $\%$ & $n$ & $\%$ & $n$ & $\%$ \\
\hline Median age (years) & 24 & & 16 & & 23 & \\
\hline \multicolumn{7}{|l|}{ History of sexual behavior } \\
\hline Yes & 34 & 77.3 & 3 & 18.8 & 37 & 61.7 \\
\hline No & 10 & 22.7 & 13 & 81.2 & 23 & 38.3 \\
\hline \multicolumn{7}{|l|}{ Symptoms } \\
\hline Post-coital bleeding & 21 & 47.7 & 0 & 0.0 & 21 & 35.0 \\
\hline Abnormal vaginal bleeding & 16 & 36.4 & 8 & 50.0 & 24 & 40.0 \\
\hline Cervical polypoid mass & I & 2.3 & 7 & 43.8 & 8 & 13.3 \\
\hline Cervical cancer screening & 3 & 6.8 & 0 & 0.0 & 3 & 5.0 \\
\hline Others & 3 & 6.8 & I & 6.2 & 4 & 6.7 \\
\hline \multicolumn{7}{|l|}{ Histology } \\
\hline \multicolumn{7}{|l|}{ Type of carcinoma } \\
\hline Squamous cell carcinoma & 22 & 50.0 & & & 22 & 36.6 \\
\hline Adenocarcinoma & 18 & 40.9 & & & 18 & 30.0 \\
\hline Others & 4 & 9.1 & & & 4 & 6.7 \\
\hline \multicolumn{7}{|l|}{ Type of sarcoma } \\
\hline Embryonal rhabdomyosarcoma & & & 8 & 50.0 & 8 & 13.3 \\
\hline Endometrial stromal sarcoma & & & 4 & 25.0 & 4 & 6.7 \\
\hline Others & & & 4 & 25.0 & 4 & 6.7 \\
\hline \multicolumn{7}{|l|}{ Stage } \\
\hline I & 26 & 59.1 & 14 & 87.5 & 40 & 66.7 \\
\hline II & 13 & 29.5 & 0 & 0.0 & 13 & 21.7 \\
\hline III & 2 & 4.5 & 0 & 0.0 & 2 & 3.3 \\
\hline IV & 3 & 6.8 & 2 & 12.5 & 5 & 8.3 \\
\hline \multicolumn{7}{|l|}{ Surgery } \\
\hline Conization & 3 & 6.8 & 0 & 0.0 & 3 & 5.0 \\
\hline Radical trachelectomy & 8 & 18.2 & 0 & 0.0 & 8 & 13.3 \\
\hline Radical hysterectomy & 20 & 45.5 & I & 6.3 & 21 & 35.0 \\
\hline Polypectomy & 0 & 0.0 & 15 & 93.8 & 15 & 25.0 \\
\hline
\end{tabular}

mal vaginal bleeding, and only three patients had their cancers detected by cervical cancer screening. However, abnormal vaginal bleeding and cervical polypoid mass were the common symptoms in patients with cervical sarcoma. Over $88 \%$ of patients with cervical cancer had stage I-II disease; only seven patients had stage III-IV.

Of the 44 patients with cervical carcinoma, 3 were unable to tolerate any treatment owing to extensive metastases and multiple organ failure. Twenty patients underwent laparoscopic or abdominal radical hysterectomy, among whom 14 had ovarian conservation surgery. Radical trachelectomy was performed in eight patients with stage IB1 tumors $<2 \mathrm{~cm}$, and three patients with stage IA1 tumors underwent conization. Among the eleven patients who underwent fertility-sparing surgeries, one experienced a recurrence and got remission after chemoradiotherapy. Seven patients attempted to become pregnant and four (57.1\%) were able to conceive. A total of six pregnancies occurred, resulting in four live births
(66.7\%) and two miscarriages (33.3\%) owing to premature membrane ruptures during the second trimester (Table 2). Additionally, 14 patients with postoperative pathological risk factors received adjuvant pelvic radiotherapy following radical surgery, and 10 received concurrent chemoradiotherapy as their primary treatment. Among the 31 patients who underwent surgeries, LN metastasis was diagnosed in 7 patients; moreover, LVSI was observed in 6 patients and DSI in 11 patients. Among patients with sarcoma, nine with ERMS or alveolar soft part sarcoma underwent polypoid mass resection with adjuvant chemotherapy consisting of vincristine, actinomycin, and cyclophosphamide/ifosfamide. Six patients with endometrial stromal sarcoma or adenosarcoma underwent conization, followed by adjuvant chemotherapy consisting of cisplatin, epirubicin, and ifosfamide. Laparoscopic radical hysterectomy and pelvic LN dissection was performed in one patient with endometrial stromal sarcoma who had lung metastasis. 
All the patients were followed either through telephone interviews or at outpatient clinics. The median followup time was 60 months (range 1-384 months) and four patients were lost to follow up. Forty-five patients (75\%) have remained tumor-free to date, while seven $(11.7 \%)$ experienced recurrence between 2 months and 3 years after completion of treatment. Eleven patients died, including nine of extensive metastases and multiple organ failure and two of septic shock. The estimated 5-year overall survival rate of the entire cohort was $79.8 \%$ (Figure 1). There was no statistically significant difference in 5-year survival between patients with cervical carcinoma and those with sarcoma ( $74.3 \%$ vs $93.3 \%, P=0.14$, Figure 2$)$. Furthermore, univariate analysis of prognostic risk factors revealed that non-squamous histology ( $53.0 \%$ vs $94.4 \%, P=0.003)$, stage IIB-IV disease ( $36.4 \%$ vs $86.0 \%, P=0.001$ ), and pelvic $\mathrm{LN}$ metastasis $(37.3 \%$ vs $94.7 \%, P=0.001)$ were significantly associated with poorer disease-specific survival (Table 3). Multivariate analysis with Cox proportional regression was used to evaluate risk factors identified on univariate analysis. The data demonstrated that stage IIB-IV disease (RR 6.71, 95\% CI 1.366-32.970, $P=0.019)$ and LN metastasis (RR

Table 2 Fertility results and pregnancy outcomes of eleven cervical carcinoma patients with fertility-sparing surgeries

\begin{tabular}{|l|l|l|}
\hline Pregnancy outcomes & Number & Percent (\%) \\
\hline Attempted to conceive & 7 & $7 / 11(63.6)$ \\
Achieved pregnancy & 4 & $4 / 7(57.1)$ \\
Total pregnancies & 6 & \\
Live births & 4 & $4 / 6(66.7)$ \\
Miscarriages & 2 & $2 / 6(33.3)$ \\
Recurrence & $\mathrm{I}$ & $\mathrm{I} / \mathrm{II}(9.1)$ \\
\hline
\end{tabular}

9.09, 95\% CI 1.050-78.732, $P=0.045$ ) were independent risk factors for poor prognosis in those young patients with cervical carcinoma, whereas histologic subtype was excluded (RR 3.07, 95\% CI 0.314-29.978, $P=0.335$, Table 4).

\section{Discussion}

Cervical cancer is almost always caused by a persistent HPV infection. There are four steps in cervical cancer development: infection with HPV, viral persistence, precancerous changes, and invasive cervical cancer. Generally, precancerous changes often develop within 5 years of HPV infection, while invasive cervical cancer typically arises over $5-10$ years in $20 \%-30 \%$ of patients with precancerous growths. ${ }^{2}$ However, among cervical cancer patients $\leq 25$ years, the majority of them do not have a long history of sexual activity, even without sexual debut. As a result, some of the cervical cancer patients aged $\leq 25$ years probably do not have a more than 5-10 years history of HPV infection or precancerous changes. Therefore, we postulate that cervical cancer develops more aggressively in young women $\leq 25$ years than older patients. In addition, most previous studies defined young cervical cancer patients as those $\leq 30$ or $\leq 35$ years, and conflicting prognoses were reported for these age groups, ${ }^{6-9,18}$ in which much heterogeneity also exists. Hence, we focused on very young women with cervical cancer ( $\leq 25$ years) for our study.

The distribution of cervical cancer histologic subtypes in women $\leq 25$ years differs from that of patients of all ages. According to the Surveillance, Epidemiology, and End Result Program Cancer Statistics Review, ${ }^{19}$ squamous cell carcinoma is dominant among cervical carcinomas in patients of all ages (65.5\%), followed by adenocarcinoma (28.5\%). However,

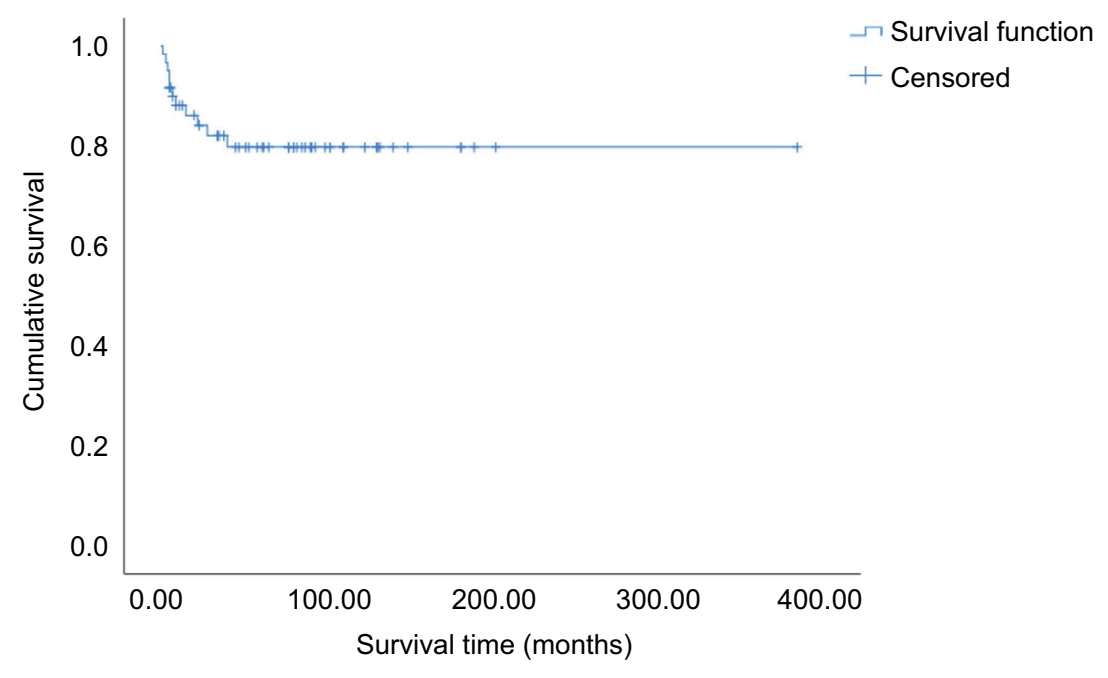

Figure I Kaplan-Meier curve showing overall survival in 60 cervical cancer patients aged $\leq 25$ years. 


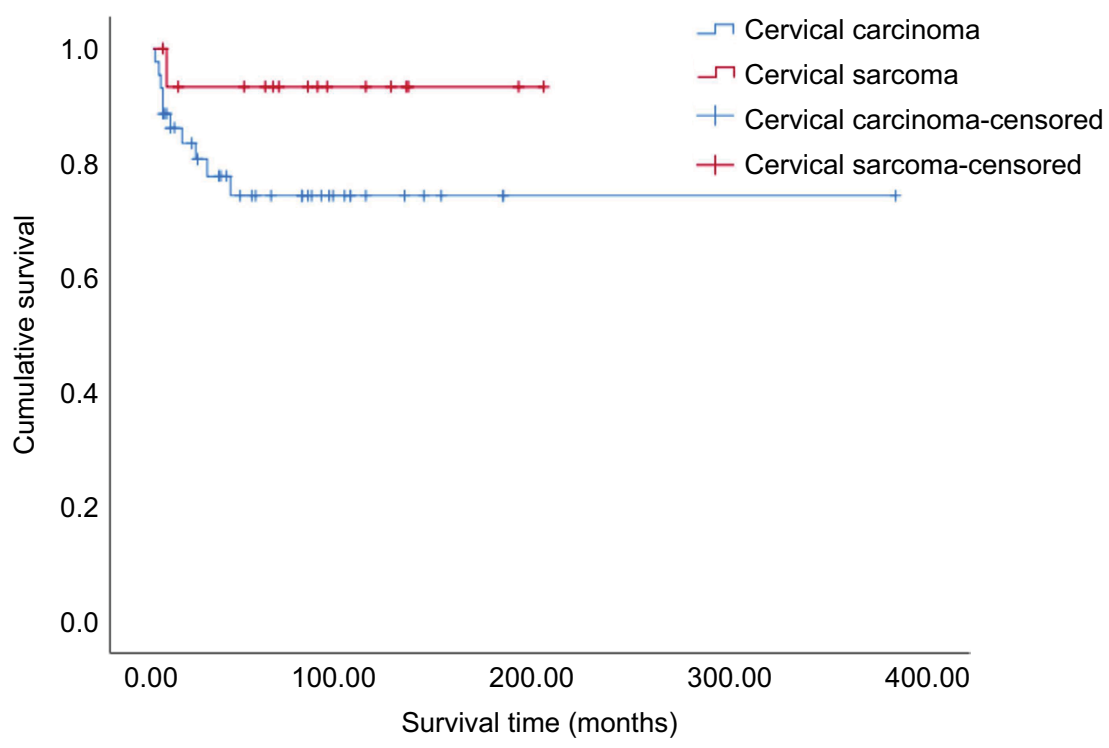

Figure 2 Kaplan-Meier curve showing overall survival among women $\leq 25$ years with cervical carcinoma and cervical sarcoma.

Table 3 Univariate analysis of prognostic risk factors in 44 young cervical carcinoma patients

\begin{tabular}{|l|l|l|}
\hline Prognostic factors & 5-Year survival rate & P-value \\
\hline Histologic subtype & & \\
Squamous carcinoma & 94.4 & $0.003^{\mathrm{a}}$ \\
Non-squamous carcinoma & 53.0 & \\
Stage & & \\
IAI-IIA2 & 86.0 & $0.00 \mathrm{I}^{\mathrm{a}}$ \\
IIB-IV & 36.4 & \\
Pelvic LN metastasis & & \\
Yes & 37.3 & $0.00 \mathrm{I}^{\mathrm{a}}$ \\
No & 94.7 & \\
Differentiation & & \\
GI & 74.9 & 0.909 \\
G2/G3 & 74.6 & \\
\hline
\end{tabular}

Note: ${ }^{a}<0.05$ indicated statistically significant differences.

Abbreviation: LN, lymph node.

Table 4 Multivariate analysis of prognostic risk factors in 44 young cervical carcinoma patients

\begin{tabular}{|l|l|l|l|}
\hline Prognostic factors & RR & $\mathbf{9 5 \%} \mathbf{C l}$ & P-value \\
\hline Stage & 6.71 & $(1.366,32.970)$ & $0.019^{\mathrm{a}}$ \\
Pelvic LN metastasis & 9.09 & $(1.050,78.732)$ & $0.045^{\mathrm{a}}$ \\
$\begin{array}{l}\text { Non-squamous } \\
\text { carcinoma }\end{array}$ & 3.07 & $(0.314,29.978)$ & 0.335 \\
\hline
\end{tabular}

Note: $a p<0.05$ indicated statistically significant differences.

Abbreviation: LN, lymph node.

our data revealed that adenocarcinoma accounted for $\sim 40 \%$ of cervical carcinomas afflicting young women, which is much higher than the proportion of adenocarcinomas among all age groups and indicates that adenocarcinoma is more likely to be found in younger women. Indeed, the proportion of adenocarcinoma is reportedly rising in young women; ${ }^{10,11,20,2}$ moreover, patients with adenocarcinoma reportedly have poorer prognoses and lower survival rates than those with squamous cell carcinoma. ${ }^{6,13-18}$

Interestingly, $>60 \%$ of the cervical adenocarcinomas were CCCCs, which is a rare disease usually accounting for $4 \%-9 \%$ of adenocarcinomas of the cervix. ${ }^{22}$ Previous studies found that $\mathrm{CCCC}$ is related to intrauterine exposure to diethylstilbestrol; however, this agent was banned in the $1970 \mathrm{~s},{ }^{23}$ and none of our patients with CCCC had been exposed to it in utero. Although HPV infection is associated with almost all cervical squamous cell carcinomas and $85 \%-90 \%$ of cervical adenocarcinomas, there appears to be no association between high-risk HPV infection and CCCC. ${ }^{24,25}$ Consistent with previous studies, the majority of patients with $\mathrm{CCCC}$ had not been sexually active, further indicating that CCCC is unlikely to be caused by HPV. Instead, genetic factors, instability of microsatellite repeat sequences, and exogenous risk factors may play an important role in the carcinogenesis of CCCC. ${ }^{26,27}$ The 5-year overall survival rate of patients with CCCC was $67 \%-72 \%, 22,23$ in our cohort of patients $\leq 25$ years, seven of eleven $(63.6 \%)$ have remained tumor-free, which is similar to the tumor-free rate of CCCC patients of all ages.

Additionally, $26.7 \%$ of cervical cancers among the very young women in our study were sarcomas. Cervical sarcoma is a rare gynecological neoplasm, accounting for $0.4 \%$ of cervical cancers overall. ${ }^{19}$ Furthermore, the distribution of the histologic subtypes of cervical sarcoma in very young women is different from that in patients overall. Bansal et $\mathrm{al}^{28}$ found 
that carcinosarcoma is the most common histologic subtype in patients of all ages, followed by leiomyosarcoma and adenosarcomas. In our cohort, however, ERMS comprised 50\% of cervical sarcomas in very young women. Rhabdomyosarcoma is the most common childhood soft-tissue sarcoma, and includes ERMS, botryoid rhabdomyosarcoma, alveolar rhabdomyosarcoma, spindle cell rhabdomyosarcoma, and undifferentiated sarcoma. ${ }^{29}$ ERMS comprises up to $58 \%$ of all rhabdomyosarcomas; cervical ERMS most commonly occurs in the second and third decades of life. ${ }^{30,31}$ Consistent with previous studies, the age at ERMS diagnosis ranged from 13 to 20 years in our cohort.

Fertility preservation is an important factor in young women with cervical cancer. The cornerstone of conservative surgery is radical trachelectomy, which may be performed either vaginally, abdominally, laparoscopically, or robotically. The safety and feasibility of radical trachelectomy have been well described in a series of studies. ${ }^{32-34}$ All eight patients in our study who underwent radical trachelectomy conformed to the universal selection criteria, which are 1) clinical stage between IA1 (with LVSI) and IB1 (tumor <2 cm); 2) squamous cell carcinoma, adenocarcinoma, or adenosquamous carcinoma; 3 ) tumor limited to the cervix; 4) and no evidence of clinical pelvic LN metastasis. ${ }^{35}$ Since radical trachelectomy is not the standard surgical treatment, both its oncological and obstetrical outcomes should be taken into consideration when this procedure is performed. A recent review of the published literature revealed an overall recurrence rate of $<5 \%$ and death rate of $<3 \%$ following radical trachelectomy, which are comparable to the rates of radical hysterectomy. ${ }^{36-39}$ Moreover, Bentivegna et $\mathrm{al}^{40}$ reported that the pregnancy rates following vaginal, abdominal, and minimally invasive radical trachelectomy were $57 \%, 44 \%$, and $65 \%$, respectively. Furthermore, the live birth rates following these three trachelectomy procedures ranged from $67 \%$ to $78 \%$. In our cohort, only one patient who underwent radical trachelectomy $(12.5 \%)$ experienced a recurrence and got remission after chemoradiotherapy. Moreover, 57\% of patients who attempted to conceive succeeded, and the live birth rate among them was $66 \%$, which is similar to previously published rates. Therefore, radical trachelectomy should be regarded as an optional surgical approach in the management of early cervical cancer in young women to preserve their fertility.

The 5-year overall survival rate of cervical cancer patients of all ages varied from $55 \%$ to $75 \%$ worldwide. ${ }^{41-43}$ In our study, the 5-year overall survival rate was $79.8 \%$, which indicates that the prognosis of cervical cancer in very young women is not inferior to that in older patients. However, the survival rates varied widely according to the cervical cancer histologic subtypes in our young cohort. The 5-year survival rate among patients with cervical carcinoma was much lower than that among patients with cervical sarcoma (74.3\% vs $93.3 \%, P=0.14$ ), although this difference was not statistically significant owing to the small cervical sarcoma patient sample size. Further analysis found a statistically significant difference of survival rate between squamous cell and non-squamous cell carcinoma of the cervix (94.4\% vs $53.0 \%, P=0.003)$. Among the ten patients who died of cervical carcinoma, nine had adenocarcinoma, adenosquamous carcinoma, or neuroendocrine carcinoma. These results indicate that histology substantially affects the survival rate, and that non-squamous cell carcinoma has a poorer prognosis than squamous cell carcinoma, which is consistent with previous studies. ${ }^{6,13-18}$ We also found that histologic subtype, stage, and LN metastasis status all had significant impacts on survival based on univariate analysis. However, the histologic subtype was not found to be a statistically significant factor on multivariate analysis. Moreover, although stage and LN metastasis achieved to be statistically significant risk factors on multivariate analysis, the CIs are quite wide. Perhaps this is due to the small sample size of our cohort.

Given the rarity of cervical cancer in women $\leq 25$ years, we were only able to conduct a retrospective study on this younger population; therefore, it was difficult to rule out selection bias. In addition, it is hard to reach a statistical significance in the univariate and multivariate analysis due to the small sample size of our cohort. Moreover, this study did not include a comparison group of older patients; hence, we only compared clinicopathological characteristics and prognoses with patients reported in previous studies. However, ours is the largest study focusing on cervical cancer patients aged $\leq 25$ years, and we were able to identify the histologic subtype distributions and prognoses in this specific age group. These data provide valuable information pertaining to the treatment of cervical cancer in young women as well as to cervical cancer screening programs.

\section{Conclusion}

In conclusion, adenocarcinoma and sarcoma of cervix, rather than squamous cell carcinoma, comprise the majority of cervical cancer subtypes afflicting very young women. The overall prognoses of cervical cancer in this age group are not inferior to those of older patients. However, survival rates tend to vary widely according to histologic subtypes; the survival rate of patients with non-squamous cell carci- 
noma is much lower than that of patients with squamous cell carcinoma. Moreover, greater attention should be paid to cervical carcinoma patients with higher disease stages and LN metastasis, as these factors predict significantly poorer prognoses.

\section{Acknowledgments}

We thank the medical record room staff for their assistance in retrieving the medical records of the patients. This work was supported by grants from the National Natural Science Foundation of China (No. 81772783 and No. 81472446) and the Chinese Academy of Medical Sciences Initiative for Innovative Medicine (CAMS-2017-I2M-1-002) to Y Xiang.

\section{Disclosure}

The authors report no conflicts of interest in this work.

\section{References}

1. Bray F, Ferlay J, Soerjomataram I, et al. Global cancer statistics 2018: GLOBOCAN estimates of incidence and mortality worldwide for 36 cancers in 185 countries. CA Cancer J Clin. 2018;68(6):394-424.

2. Schiffman M, Castle PE, Jeronimo J, Rodriguez AC, Wacholder S. Human papillomavirus and cervical cancer. Lancet. 2007;370(9590): 890-907.

3. Patel A, Galaal K, Burnley C, et al. Cervical cancer incidence in young women: a historical and geographic controlled UK regional population study. Br J Cancer. 2012;106(11):1753-1759.

4. Li S, Hu T, Lv W, et al. Changes in prevalence and clinical characteristics of cervical cancer in the People's Republic of China: a study of 10,012 cases from a nationwide Working Group. Oncologist. 2013;18(10):1101-1107.

5. Motoki Y, Mizushima S, Taguri M, et al. Increasing trends in cervical cancer mortality among young Japanese women below the age of 50 years: an analysis using the Kanagawa population-based cancer Registry, 1975-2012. Cancer Epidemiol. 2015;39(5):700-706.

6. Lau HY, Juang CM, Chen YJ, et al. Aggressive characteristics of cervical cancer in young women in Taiwan. Int $J$ Gynaecol Obstet. 2009;107(3):220-223.

7. Rutledge FN, Mitchell MF, Munsell M, et al. Youth as a prognostic factor in carcinoma of the cervix: a matched analysis. Gynecol Oncol. 1992;44(2):123-130.

8. Meanwell CA, Kelly KA, Wilson S, et al. Young age as a prognostic factor in cervical cancer: analysis of population based data from 10,022 cases. Br Med J. 1988;296(6619):386-391.

9. Spanos WJ, Jr., King A, Keeney E, Wagner R, Slater JM. Age as a prognostic factor in carcinoma of the cervix. Gynecol Oncol. 1989;35(1):66-68

10. Bulk S, Visser O, Rozendaal L, Verheijen RH, Meijer CJ. Cervical cancer in the Netherlands 1989-1998: decrease of squamous cell carcinoma in older women, increase of adenocarcinoma in younger women. Int $J$ Cancer. 2005;113(6):1005-1009.

11. Liu S, Semenciw R, Mao Y. Cervical cancer: the increasing incidence of adenocarcinoma and adenosquamous carcinoma in younger women. CMAJ. 2001;164(8):1151-1152.

12. Seoud M, Tjalma WA, Ronsse V. Cervical adenocarcinoma: moving towards better prevention. Vaccine. 2011;29(49):9148-9158.

13. Davy ML, Dodd TJ, Luke CG, Roder DM. Cervical cancer: effect of glandular cell type on prognosis, treatment, and survival. Obstet Gynecol. 2003;101(1):38-45.
14. Lee KB, Lee JM, Park CY, et al. What is the difference between squamous cell carcinoma and adenocarcinoma of the cervix? A matched case-control study. Int J Gynecol Cancer. 2006;16(4):1569-1573.

15. Nakanishi T, Ishikawa H, Suzuki Y, et al. A comparison of prognoses of pathologic stage IB adenocarcinoma and squamous cell carcinoma of the uterine cervix. Gynecol Oncol. 2000;79(2):289-293.

16. Vinh-Hung V, Bourgain C, Vlastos G, et al. Prognostic value of histopathology and trends in cervical cancer: a SEER population study. $B M C$ Cancer. 2007;7(1):164.

17. Grisaru D, Covens A, Chapman B, et al. Does histology influence prognosis in patients with early-stage cervical carcinoma? Cancer. 2001;92(12):2999-3004.

18. Yang L, Jia X, Li N, et al. Comprehensive clinic-pathological characteristics of cervical cancer in southwestern China and the clinical significance of histological type and lymph node metastases in young patients. PLoS One. 2013;8(10):e75849.

19. Surveillance, epidemiology, and end results program, SEER Cancer statistics review, 1975-2015, 2018, cervix uteri, table 5.16. Available from: https://seer.cancer.gov/csr/1975_2015/results_merged/ sect_05_cervix_uteri.pdf. Accessed September 10, 2018.

20. Smith HO, Tiffany MF, Qualls CR, Key CR. The rising incidence of adenocarcinoma relative to squamous cell carcinoma of the uterine cervix in the United States - a 24-year population-based study. Gynecol Oncol. 2000;78(2):97-105.

21. Sherman ME, Wang SS, Carreon J, Devesa SS. Mortality trends for cervical squamous and adenocarcinoma in the United States. Relation to incidence and survival. Cancer. 2005;103(6):1258-1264.

22. Reich O, Tamussino K, Lahousen M, et al. Clear cell carcinoma of the uterine cervix: pathology and prognosis in surgically treated stage IB-IIB disease in women not exposed in utero to diethylstilbestrol. Gynecol Oncol. 2000;76(3):331-335.

23. Jiang X, Jin Y, Li Y, et al. Clear cell carcinoma of the uterine cervix: clinical characteristics and feasibility of fertility-preserving treatment. Onco Targets Ther. 2014;7:111-116.

24. Pirog EC, Kleter B, Olgac S, et al. Prevalence of human papillomavirus DNA in different histological subtypes of cervical adenocarcinoma. Am J Pathol. 2000;157(4):1055-1062.

25. Ueno S, Sudo T, Oka N, et al. Absence of human papillomavirus infection and activation of PI3K-Akt pathway in cervical clear cell carcinoma. Int J Gynecol Canc. 2013;23(6):1084-1091.

26. Boyd J, Takahashi H, Waggoner SE, et al. Molecular genetic analysis of clear cell adenocarcinomas of the vagina and cervix associated and unassociated with diethylstilbestrol exposure in utero. Cancer. 1996;77(3):507-513.

27. Hanselaar A, van Loosbroek M, Schuurbiers O, et al. Clear cell adenocarcinoma of the vagina and cervix. An update of the central Netherlands registry showing twin age incidence peaks. Cancer. 1997;79(11):2229-2236.

28. Bansal S, Lewin SN, Burke WM, et al. Sarcoma of the cervix: natural history and outcomes. Gynecol Oncol. 2010;118(2):134-138.

29. Parham DM, Barr FG. Classification of rhabdomyosarcoma and its molecular basis. Adv Anat Pathol. 2013;20(6):387-397.

30. Dehner LP, Jarzembowski JA, Hill DA. Embryonal rhabdomyosarcoma of the uterine cervix: a report of 14 cases and a discussion of its unusual clinicopathological associations. Mod Pathol. 2012;25(4):602-614.

31. Narin MA, Karalok A, Basaran D, et al. Embryonal rhabdomyosarcoma of the cervix in young women. J Adolesc Young Adult Oncol. 2016;5(3):261-266.

32. Ramirez PT, Schmeler KM, Soliman PT, Frumovitz M. Fertility preservation in patients with early cervical cancer: radical trachelectomy. Gynecol Oncol. 2008;110(3 Suppl 2):S25-S28.

33. Gizzo S, Ancona E, Saccardi C, et al. Radical trachelectomy: the first step of fertility preservation in young women with cervical cancer (review). Oncol Rep. 2013;30(6):2545-2554.

34. Halaska M, Robova H, Pluta M, Rob L. The role of trachelectomy in cervical cancer. Ecancermedicalscience. 2015;9:506. 
35. Mejia-Gomez J, Feigenberg T, Feigenber T, Arbel-Alon S, Kogan L, Benshushan A. Radical trachelectomy: a fertility-sparing option for early invasive cervical cancer. Isr Med Assoc J. 2012;14(5):324-328.

36. Hertel H, Köhler C, Grund D, et al. Radical vaginal trachelectomy (RVT) combined with laparoscopic pelvic lymphadenectomy: prospective multicenter study of 100 patients with early cervical cancer. Gynecol Oncol. 2006;103(2):506-511.

37. Hauspy J, Beiner M, Harley I, et al. Sentinel lymph nodes in early stage cervical cancer. Gynecol Oncol. 2007;105(2):285-290.

38. Marchiole P, Benchaib M, Buenerd A, et al. Oncological safety of laparoscopic-assisted vaginal radical trachelectomy (LARVT or Dargent's operation): a comparative study with laparoscopic-assisted vaginal radical hysterectomy (LARVH). Gynecol Oncol. 2007;106(1):132-141.

39. Diaz JP, Sonoda Y, Leitao MM, et al. Oncologic outcome of fertilitysparing radical trachelectomy versus radical hysterectomy for stage IB1 cervical carcinoma. Gynecol Oncol. 2008;111(2):255-260.
40. Bentivegna E, Maulard A, Pautier P, et al. Fertility results and pregnancy outcomes after conservative treatment of cervical cancer: a systematic review of the literature. Fertil Steril. 2016;106(5):1195-1211.

41. Benard VB, Watson M, Saraiya M, et al. Cervical cancer survival in the United States by race and stage (2001-2009): findings from the CONCORD-2 study. Cancer. 2017;123 (Suppl 24):5119-5137.

42. Melan K, Janky E, Macni J, et al. Epidemiology and survival of cervical cancer in the French West-Indies: data from the Martinique cancer registry (2002-2011). Glob Health Action. 2017;10(1): 1337341 .

43. Diaz A, Baade PD, Valery PC, et al. Comorbidity and cervical cancer survival of Indigenous and non-Indigenous Australian women: a semi-national registry-based cohort Study (2003-2012). PLoS One. 2018;13(5):e0196764.
Cancer Management and Research

\section{Publish your work in this journal}

Cancer Management and Research is an international, peer-reviewed open access journal focusing on cancer research and the optimal use of preventative and integrated treatment interventions to achieve improved outcomes, enhanced survival and quality of life for the cancer patient. The manuscript management system is completely online and includes
Dovepress

a very quick and fair peer-review system, which is all easy to use. Visit $\mathrm{http}: / / \mathrm{www}$.dovepress.com/testimonials.php to read real quotes from published authors. 